\title{
A Technique for Better Energy Management of Single-Stage Topology of Stand-Alone Photovoltaic System
}

\author{
Omar Azeem ${ }^{1}$, Ali Faisal Murtaza², Ghulam Abbas ${ }^{1 *}$, Umair Tahir $^{1}$ \\ ${ }^{1}$ Department of Electrical Engineering, \\ The University of Lahore, 1-KM Defence Road, Lahore, 54000, PAKISTAN \\ ${ }^{2}$ Department of Electrical Engineering, \\ University of Central Punjab, Avenue 1, Khayban-e-Jinnah, Lahore, 54000, PAKISTAN \\ *Corresponding Author
}

DOI: https://doi.org/10.30880/ijie.2020.12.08.017

Received 5 November 2019; Accepted 20 July 2020; Available online 31 August 2020

\begin{abstract}
This paper proposes a technique for the energy management of a stand-alone photovoltaic system. The proposed system employs a power processing inverter that has a high PV voltage at the input to mitigate the magnitude of AC signal at the output, thus eliminating the use of DC-DC converter and reducing the input capacitor size of PV array. To meet the power requirement of load and to maintain the maximum power point operation of PV array, a battery bank is utilized with a bi-directional converter. An impedance model of the complete system is executed. Based on the model, the control architecture is designed which works in four modes: 1) if load demands $>$ MPP of PV, additional current is extracted from the battery; 2) if load demands < MPP of PV array, extra current is given to the battery; 3 ) only load management is utilized since the battery bank is not available because of overcharging or under-charging; 4) if irradiation varies then the first mode is used for load requirement. The technique is designed which guarantees the maximum power point tracking of the PV system even without using any intermediate stage of a DC-DC converter, hence making it a single-stage system. MPPT is achieved by effectively controlling the bi-directional converter used for battery charging and discharging purposes. To ensure better utilization of dc voltage, enhanced efficiency, and low less harmonic distortion, a sinusoidal PWM technique is used to drive the inverter. Simulation results are carried out for ensuring better energy management along with MPPT operation demonstrated under uniform operating conditions.
\end{abstract}

Keywords: Photovoltaics (PV), Maximum Power Point Tracking (MPPT), DC-DC converter, inverter, standalone PV

\section{Introduction}

Photovoltaic (PV) systems are known for serving as one of the leading renewable energy sources. This is mainly due to the fact that as compared to other power sources, they are not only cost-effective but also environment friendly, hence giving their unique role in clean energy [1] in the presence of polluting energy sources which are destroying not only the atmosphere but also human health. It was estimated that by 2017 the world will get about $400 \mathrm{GW}$ of power from PV systems [2]. Among many types of available PV systems such as on-grid, hybrid, and off-grid/stand-alone, standalone PV systems have their huge contribution in remote or rural areas not only for electrification but also for irrigation purposes because of no electricity availability. A stand-alone PV system suffers from various issues. For example, to maintain an uninterruptable power supply (UPS), a constant energy source is required. PV systems are mainly dependent on 

environmental conditions, e.g. solar irradiance. Solar irradiation is not available at nights; also passing clouds can stop sunlight to reach earth in the day time (means irradiation is varying in the day time); also, it is not possible to obtain maximum power point (MPP) and regulated power supply at the same time [3], [4]. So, to attain UPS, not only there is a need for some backup supply (for the night and cloudy time) but also there should be some way to harvest maximum possible energy from the system (in cloudy or shaded time).

As load requires $220 \mathrm{~V}$ or $440 \mathrm{~V}$ and a single PV module can only provide 18-45 V (depends upon specs.), so there is a need to add a boost DC-DC converter which gives high voltage gain at a cost of reduced efficiency. To solve the UPS problem at night, it is essential to use battery [5], [6] to store excess energy, and to act as a backup energy source in case of less or no sun irradiations. But batteries have their own problems, i.e. they are costly; they require frequent maintenance and need to be changed after some time. Also, to support high voltage systems, batteries have to be connected in series, which is not a good option as it causes overcharging and deep discharging problems, hence reducing battery life [5].

As PV modules have nonlinear characteristics [7] to harvest maximum possible energy during low irradiance or cloudy days, there is a need to trace the PV curve and find out the point where it gives maximum power. This can be done by an algorithm named the maximum power tracking algorithm (MPPT). In the literature, many MPPT techniques [8]-[12] are proposed. All have their own advantage and disadvantages. Among all, one thing must be noted that without battery backup, it is not possible to achieve MPPT. In all the proposed MPPT techniques, MPPT is achieved by varying the duty cycle of the DC-DC converter. This work is based on a single-stage topology and proposes a method to find MPPT without using a DC-DC converter stage.

Mainly two types of topologies are in use in PV systems, namely a single-stage topology and a two-stage topology [13]. Fig. 1 shows a two-stage topology consisting of a DC-DC converter (boost) stage before inverter, thus forming two power processing stages giving an advantage of low system voltage, however increasing system losses. In contrast, singlestage systems are those in which series-combination of PV modules are used to form high voltage that may save from having an extra power processing stage of dc-dc converter saving roughly 10\% losses [14], [15]. Fig. 2 shows a singlestage PV system which is considered the best candidate for an efficient PV system.

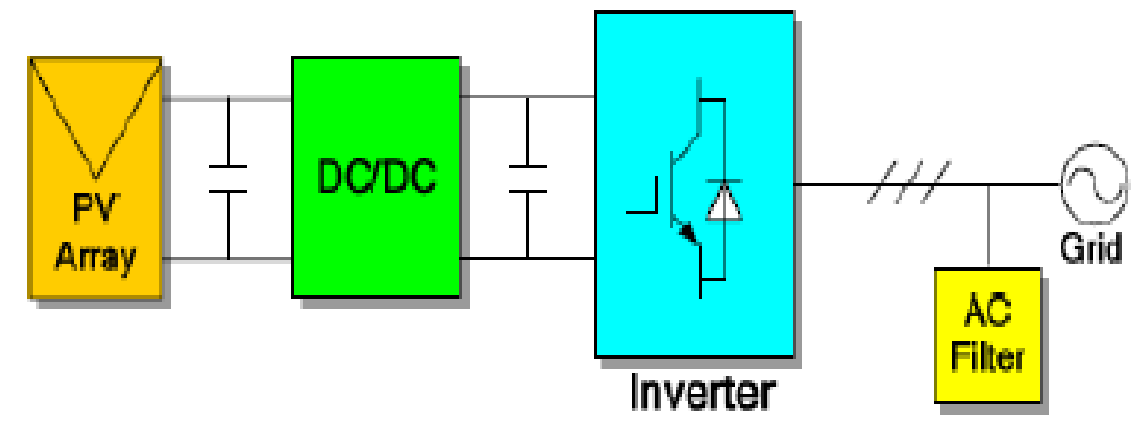

Fig. 1 - A two-stage PV system [13]

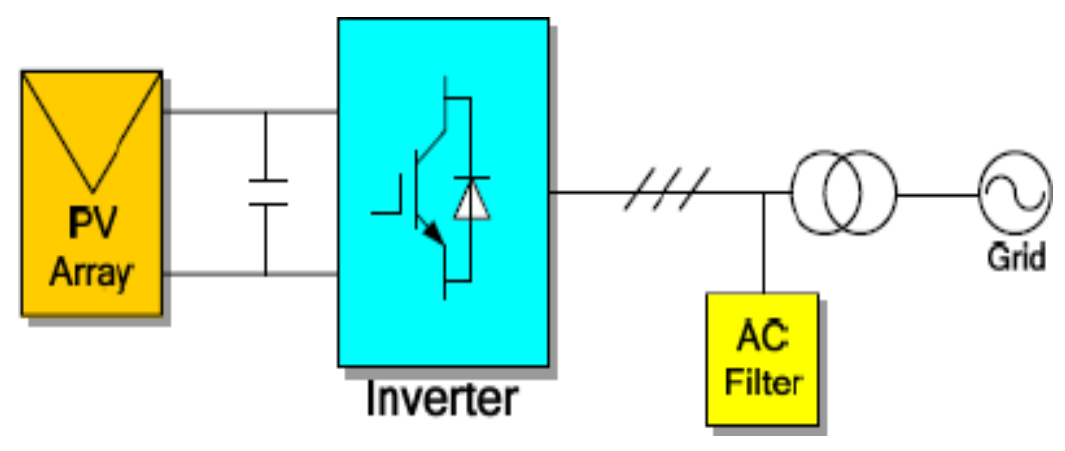

Fig. 2 - Single-stage PV system [13]

In the literature, a lot of work is done on a standalone PV system. In [16], a standalone system utilizes battery backup but it uses dump load to waste excess power in the battery and did not use any mechanism to handle this power. Reference [17] proposed a standalone PV system with only mechanical tracking and without battery. Reference [18] also proposed a system but it did not discuss battery managing in case of excess power and overcharging, etc. Reference [19] proposed a system for a water pumping application without battery backup. References [20], [21] proposed a flyback converter system [22], [23] using the $\mathrm{P} \& \mathrm{O}$ algorithm realized by using hill-climbing algorithms that come with the disadvantage of continuous power oscillations. Moreover, in large step sizes, these oscillations may increase further. In all these 
mentioned references, there is no discussion on the power efficiency of the system, voltage regulation, and losses due to the transformer. Reference [24] proposed a hybrid MPPT topology using a flyback converter but did not discuss losses caused by flyback inverter, output voltage range, and voltage regulation. Also, it did not signify what happens if the load varies and its working without battery. In [25], Das et al. did not include anything about the single-stage system.

In light of above-mentioned facts, this paper proposes a single-stage stand-alone PV system which not only overcomes above-mentioned problems of a two-stage system but also provides a new way to model a single stage standalone PV system by using a new technique named impedance modeling which is capable of achieving MPPT without any additional stage of DC-DC converter as adopted in a conventional standalone PV system. Also, ac output voltages are regulated at the desired value by varying duty cycle $(D)$ of a bidirectional DC-DC converter (used for battery charging and discharging) and modulation index $(M)$ of an inverter. The study is performed in Powersim (PSIM) software where the proposed impedance model and voltage regulation at $220 \mathrm{~V}$ are verified. Also, both simulation and theoretical results are compared.

\section{The Proposed System}

Fig. 3 shows the block diagram of a single-stage stand-alone PV system to be followed in proceeding work.

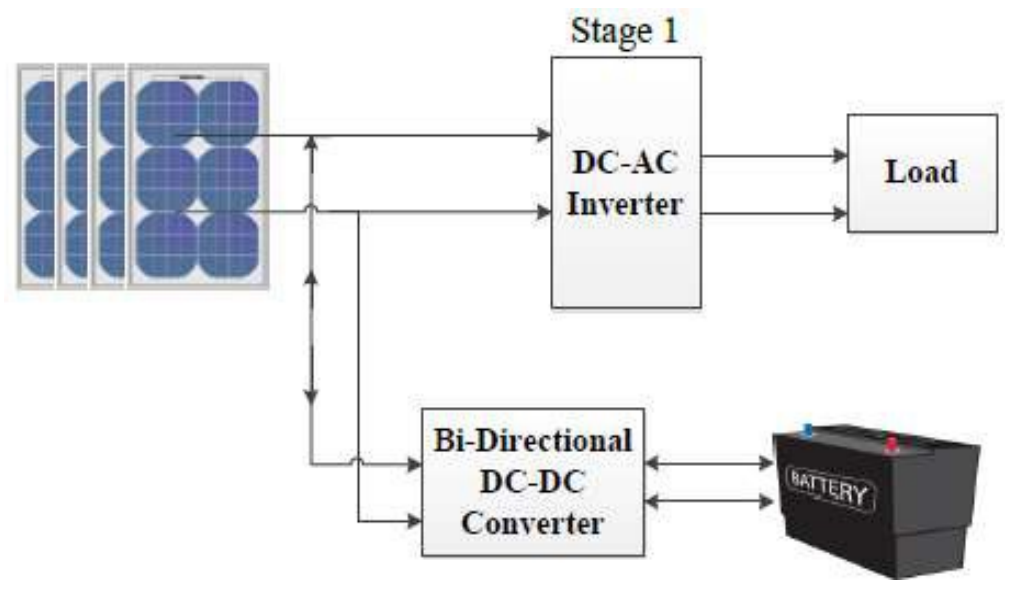

Fig. 3 - Single-stage stand-alone PV system

It consists of a series-connected string of PV panels to obtain high voltage which is forwarded to an inverter for the conversion to $\mathrm{AC}$, and excess power is transferred to battery for charging.

\subsection{PV and Inverter Impedance Model}

This is a new technique proposed in this work to develop a relationship between PV output and load (according to load by controlling the duty cycle $(D)$ and modulation index $(M)$ of bidirectional DC-DC converter and inverter, respectively). First of all, the impedance model of a simple single-stage PV and inverter is derived. It is then extended to a standalone PV system that includes a battery as well. Fig. 4 describes a system that consists of a PV module and inverter with the load attached.

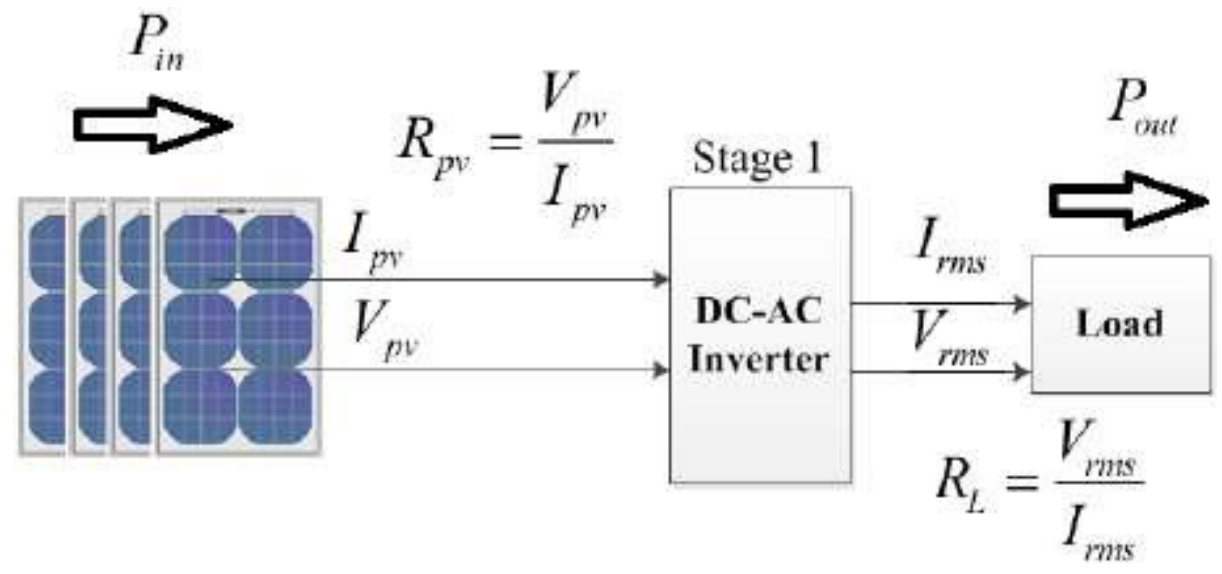

Fig. 4 - PV and inverter 
As

$$
P_{\text {in }}=P_{\text {out }}
$$

From Fig. 4,

$$
V_{p v} I_{p v}=V_{r m s} I_{r m s}
$$

From Ohm's law, the current would be

$$
\begin{gathered}
V_{p v} \frac{V_{p v}}{R_{p v}}=V_{r m s} \frac{V_{r m s}}{R_{L}} \\
\Rightarrow \frac{V_{p v}^{2}}{R_{p v}}=\frac{V_{r m s}{ }^{2}}{R_{L}}
\end{gathered}
$$

Rearranging (4) for the value of $R$ :

$$
R_{p v}=\frac{V_{p v}^{2}}{V_{r m s}^{2}} R_{L}
$$

The relation between inverter peak voltages and RMS voltages is given by:

$$
\frac{V}{\sqrt{2}}=V_{r m s}
$$

Putting (6) in (5) gives:

$$
R_{p v}=\frac{2 V_{p}^{2}}{V_{p}^{2}} R_{L}
$$

Inverter peak voltage $V_{P}$ and PV voltage are related by (8), where $M$ denotes the modulation index of an inverter.

$$
\begin{aligned}
& V_{P}=M V_{p v} \\
& \therefore R_{p v}=\frac{2}{M^{2}} R_{L}
\end{aligned}
$$

Equation (9) describes that the modulation index $(M)$ of the inverter is inversely proportional to PV or MPP voltage given by $V_{m p p}=I_{m p p} R_{P V}$. It can be seen by varying modulation index, MPP voltage can be adjusted. In certain cases, MPPT can be achieved by only adjusting $M$ (described in mode 4 in the next session).

\subsection{PV, Inverter and Battery Impedance Model}

In the former section, the impedance model of PV and inverter was derived while in this section the impedance model of PV, inverter, and battery is derived (see Fig. 5).

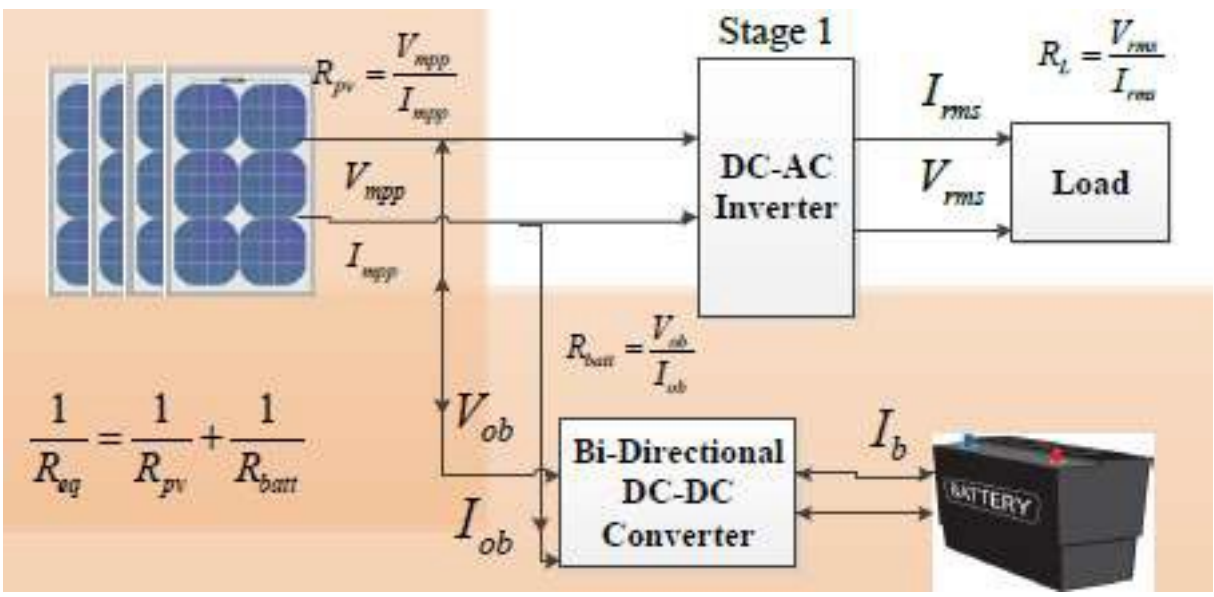

Fig. 5 - PV inverter and battery 
Consider Fig. 5, from the parallel resistance rule, we have

$$
\frac{1}{R_{e q}}=\frac{1}{R_{p v}}+\frac{1}{R_{b a t t}}
$$

Putting the values for $R_{p v}$ and $R_{b a t t}$, which are battery and PV resistances respectively, we have

$$
\begin{aligned}
& \frac{1}{R_{e q}}=\frac{I_{m p p}}{V_{m p p}}+\frac{I_{O B}}{R_{O B}} \\
& \frac{1}{R_{e q}}=\frac{V_{o b} I_{m p p}+I_{o b} V_{m p p}}{V_{m p p} V_{o b}} \\
& \Rightarrow R_{e q}=\frac{V_{m p p} V_{o b}}{V_{o b} I_{m p p}+I_{o b} V_{m p p}}
\end{aligned}
$$

Also, from (9)

$$
R_{e q}=R_{p v}=\frac{2 R_{L}}{M^{2}}
$$

Putting (9) in (13) gives

$$
\begin{aligned}
& \frac{2 R_{L}}{M^{2}}=\frac{V_{m p p} V_{o b}}{V_{o b} I_{m p p}+I_{o b} V_{m p p}} \\
& \frac{2 R_{L}}{M^{2}}\left(V_{o b} I_{m p p}+I_{o b} V_{m p p}\right)=V_{m p p} V_{o b}
\end{aligned}
$$

It can be seen from Fig. 5 that battery output voltage is equal to the on-load voltage of PV. That is to say:

$$
V_{o b}=V_{m p p}
$$

Equation (15) becomes

$$
\begin{aligned}
& \frac{2 R_{L}}{M^{2}}\left(V_{m p p} I_{m p p}+I_{o b} V_{m p p}\right)=V_{m p p}{ }^{2} \\
& \frac{2 R_{L}}{M^{2}}\left(I_{m p p}+I_{o b}\right)=V_{m p p}
\end{aligned}
$$

Input and output current for battery in terms of the duty cycle are related by (19):

$$
I_{\text {out }}=(1-D) I_{\text {batt }}
$$

This gives

$$
V_{m p p}=\frac{2 R_{L}}{M^{2}}\left(I_{m p p}+(1-D) I_{b}\right)
$$

Equation (20) describes the relationship between three components of the whole standalone single-stage PV system, i.e., PV, battery, and inverter. It shows that in any standalone PV system with an inverter, by finding load resistance and PV current and voltage, it is possible to find out the duty cycle according to battery current. To carry on the above procedure, it is required to find out load resistance which can be done by finding out load voltage and load current. Secondly, by finding out PV voltage and current, and then putting these values in (20), it leaves with only battery current and duty cycle $D$; knowing required battery current, we can find out the duty cycle at which the system will operate. As can be seen that $D$ is directly proportional and $M$ is inversely proportional to PV voltage, so we can change either $M$ or $D$ to select PV voltages.

\subsection{Modes of Operation}

Above derived impedance model is verified assuming four basic modes of operation of the standalone PV system which are described below:

1. In Mode-1, if the load is demanding more power than PV can produce at MPP, the required power would be taken from the battery through the bidirectional converter if the battery is fully charged. 
2. In Mode-2, if the load is demanding lesser power than PV can produce at MPP, excessive power is used for charging of battery through the bidirectional converter.

3. In Mode-3, let the battery is fully charged and PV is providing more power than load demands. In this case, deal with only PV power and load for load management or ac voltage regulation by varying modulation index $(M)$.

4. In Mode-4, if the sun's irradiation level decreases, the system should share the required load power from the battery while operating PV at MPP at available irradiation.

\section{Simulation Results}

The simulations were done in PSIM software where a $60 \mathrm{~W}$ PV module model is utilized from the internal library whose datasheet is shown in Fig. 6. As no DC-DC converter is used, so to get $220 \mathrm{~V}$ RMS at inverter output, a series configuration of PV modules is used while assuming $M=0.85$ and battery voltage $=24 \mathrm{~V}$.

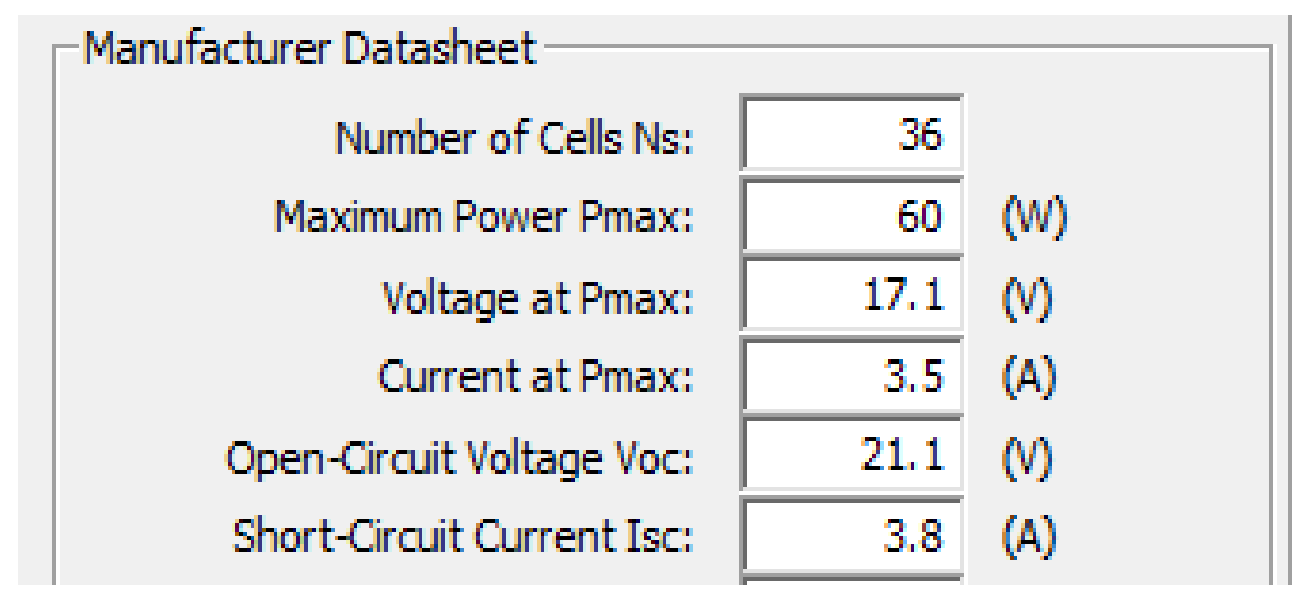

Fig. 6 - Datasheet of a $60 \mathrm{~W}$ PV module (PSIM)

As already remarked,

$$
\begin{gathered}
V_{P}=\sqrt{2} V_{r m s}=M V_{p v} \\
\Rightarrow V_{p v}=\frac{\sqrt{2} V_{r m s}}{M} \\
\therefore V_{p v}=\frac{\sqrt{2} \times 220}{0.85}=366 \mathrm{~V}
\end{gathered}
$$

Hence to produce an ac output voltage of $220 \mathrm{~V}_{\mathrm{rms}}$, PV modules need to ensure $366 \mathrm{~V}$ which can be achieved by connecting them in series (parallel arrays would be selected according to load power) at $M=0.85$. PV power at MPP is given as

$$
P_{m p p}=V_{m p p} I_{m p p}=17.1 \times 3.5 \times 22=1316 \mathrm{~W}
$$

All the above-described modes are discussed/simulated here one by one to prove above-derived relations.

\subsection{Mode 1}

As described above, if required load power is greater than that of the PV-produced at MPP, excess power has to be taken from a bi-directional converter by turning on boost mode of the bidirectional converter. Figs. 7 and 8 show ac output voltage and current waveforms. From these, load resistance can be calculated as follow:

$$
R_{L}=\frac{V_{\text {load }}}{I_{\text {load }}}=\frac{219}{10.98}=19.94 \Omega
$$




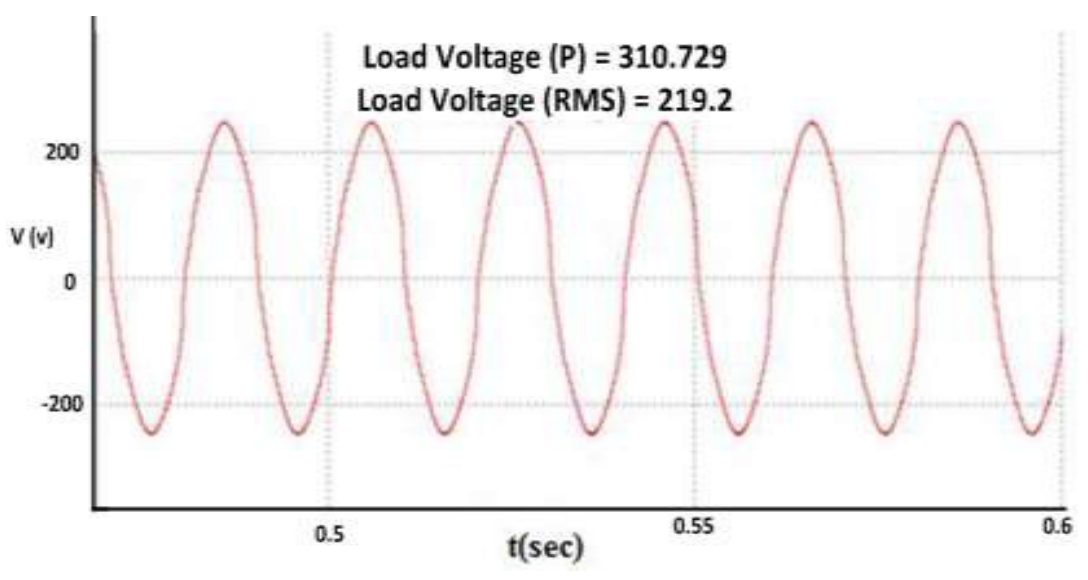

Fig. 7 - Load voltage (Mode 1)

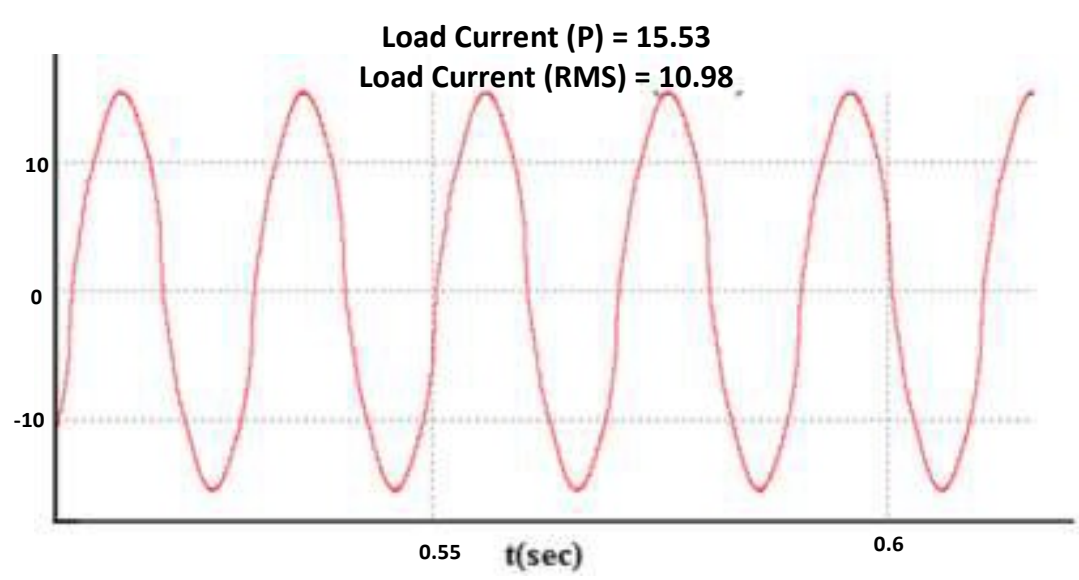

Fig. 8 - Load current (Mode 1)

From Figs. 7 and 8, it must be noted that the required load power is $2305 \mathrm{~W}$, while PV is just able to provide 1316 $\mathrm{W}$ at MPP. This condition gives rise to the fact that the system gets overloaded and collapsed and PV modules do not operate at their MPP. In this case, the battery needs to operate at a specific duty cycle. The duty cycle $(D)$ is calculated to be:

$$
\begin{aligned}
\frac{V_{o}}{V_{\text {in }}} & =\frac{366}{24}=\frac{1}{(1-D)} \\
& \Rightarrow D=0.934
\end{aligned}
$$

The duty cycle is varied slightly to get MPP. Also,

$$
\begin{gathered}
V_{m p p}=\frac{2 R_{L}}{M^{2}}\left(I_{m p p}+(1-D) I_{b}\right) \\
\frac{367 \times 0.85^{2}}{2 \times 19.94}=3.55+(1-D) I_{b} \\
6.64=3.55+(1-D) \\
I_{b}(1-D) I_{b}=3.09 \\
(1-0.938) I_{b}=3.09 \\
\Rightarrow I_{b}=49 \mathrm{~A}
\end{gathered}
$$

where $I_{b}$ is the battery current required to aid PV source in the case when PV is not providing enough power to the load. 
Figs. 9 and 10 show voltage and current waveforms at MPP; Fig. 11 shows power at MPP; Fig. 12 shows the current required from the battery to achieve MPP by varying the duty cycle of the bidirectional converter. This battery current could be varied.

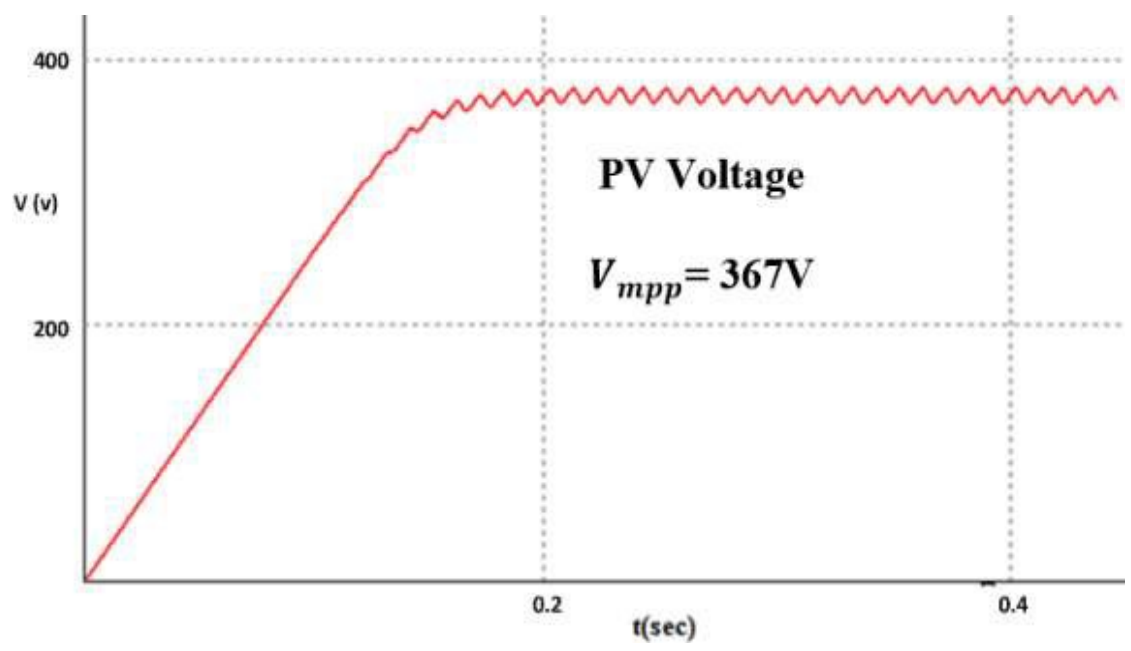

Fig. 9 - PV MPP voltage

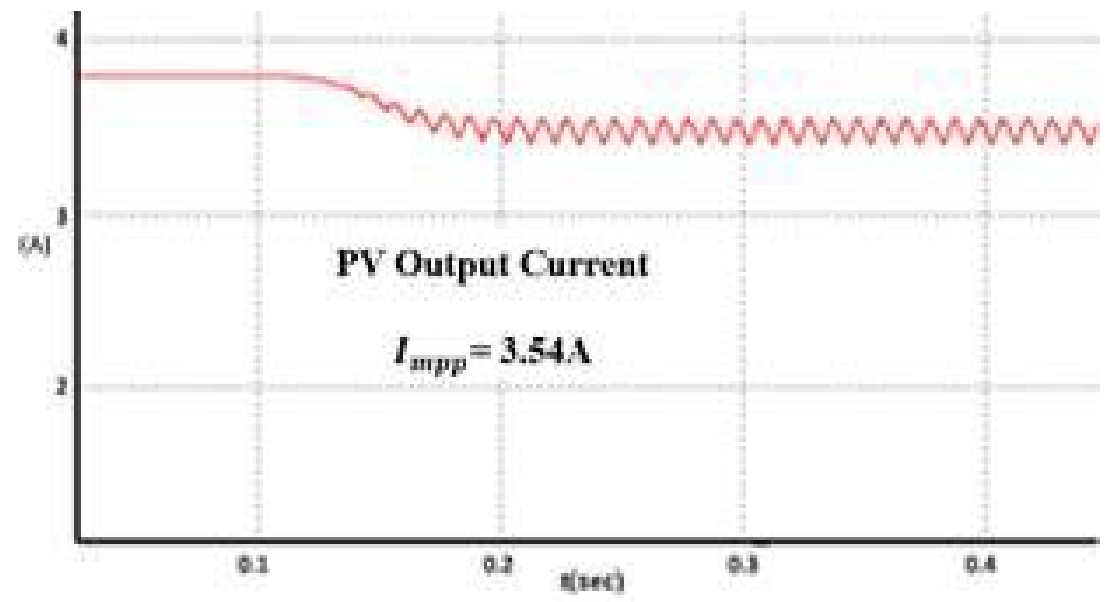

Fig. 10 - PV MPP current

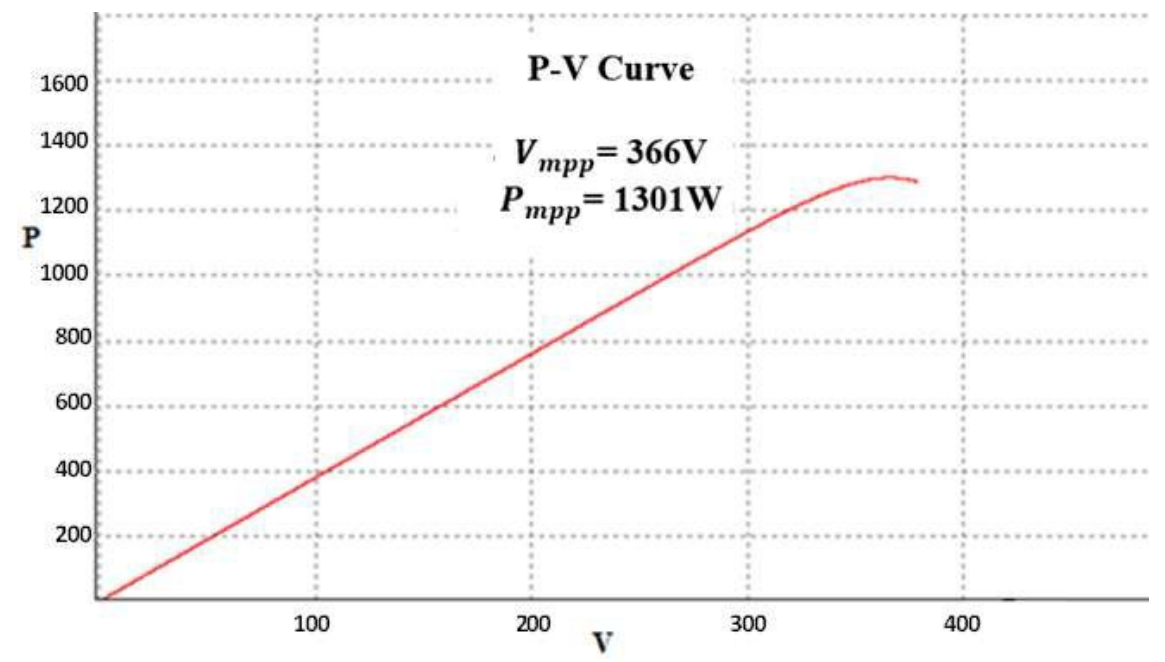

Fig. 11 - PV MPP power 


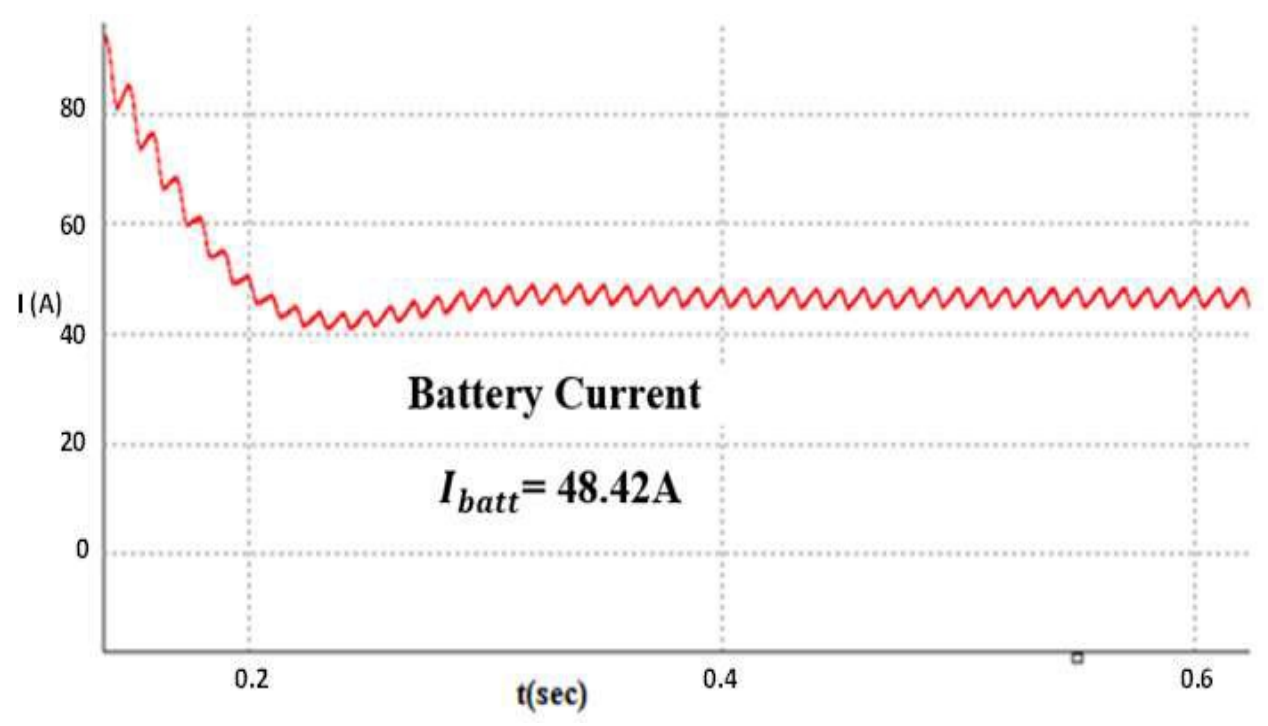

Fig. 12 - Battery current at MPP

Comparing (20) (that gives battery current) and Fig. 12, it can be seen that the theoretical current required from the battery is exactly in accordance with simulation results, thus proving the authenticity of (20).

\subsection{Mode 2}

In this mode, if the load requires lesser power than the one produced by PV, excess power is transferred to battery for charging. For this mode, the load resistance is assumed to be $128 \Omega$ and the required power by the load is $376 \mathrm{~W}$, while PV is able to provide $1300 \mathrm{~W}$ at MPP. So, this excess power is transferred to battery keeping in mind MPP is not disturbed. So, in this case, the battery is charged by turning on buck mode of DC-DC converter at the duty cycle calculated to be:

$$
D=\frac{V_{\text {out }}}{V_{\text {in }}}=\frac{24}{366}=0.0655
$$

This gives

$$
\begin{gathered}
V_{m p p}=\frac{2 R_{L}}{M^{2}}\left(I_{m p p}+(1-D) I_{b}\right) \\
\frac{368 \times 0.85^{2}}{2 \times 128}=3.55+(1-D) I_{b} \\
1.03=3.55+(1-D) I_{b} \\
(1-D) I_{b}=-2.51
\end{gathered}
$$

From buck converter, it is known that

$$
(1-D) I_{b}=I_{b a t t, \text { in }}
$$

The comparison of the above two equations results in

$$
I_{\text {batt }, \text { in }}=-2.51
$$

This is the current that enters from the high voltage side of the bi-directional converter. Here negative sign indicates reverse power flow for charging. Current going in the battery for charging is given as

$$
\begin{gathered}
I_{b}=D I_{\text {batt }, \text { in }} \Rightarrow 2.51=0.081 \times I_{\text {batt } \text {, in }} \\
\therefore I_{b}=30.9 \mathrm{~A}
\end{gathered}
$$

As can be seen from Figs.13 to 15, PV is operating at its MPP parameters consuming all power in load and battery charging at MPP. Also, the simulation result in Fig.16 verifies the theoretical result of the battery current. 


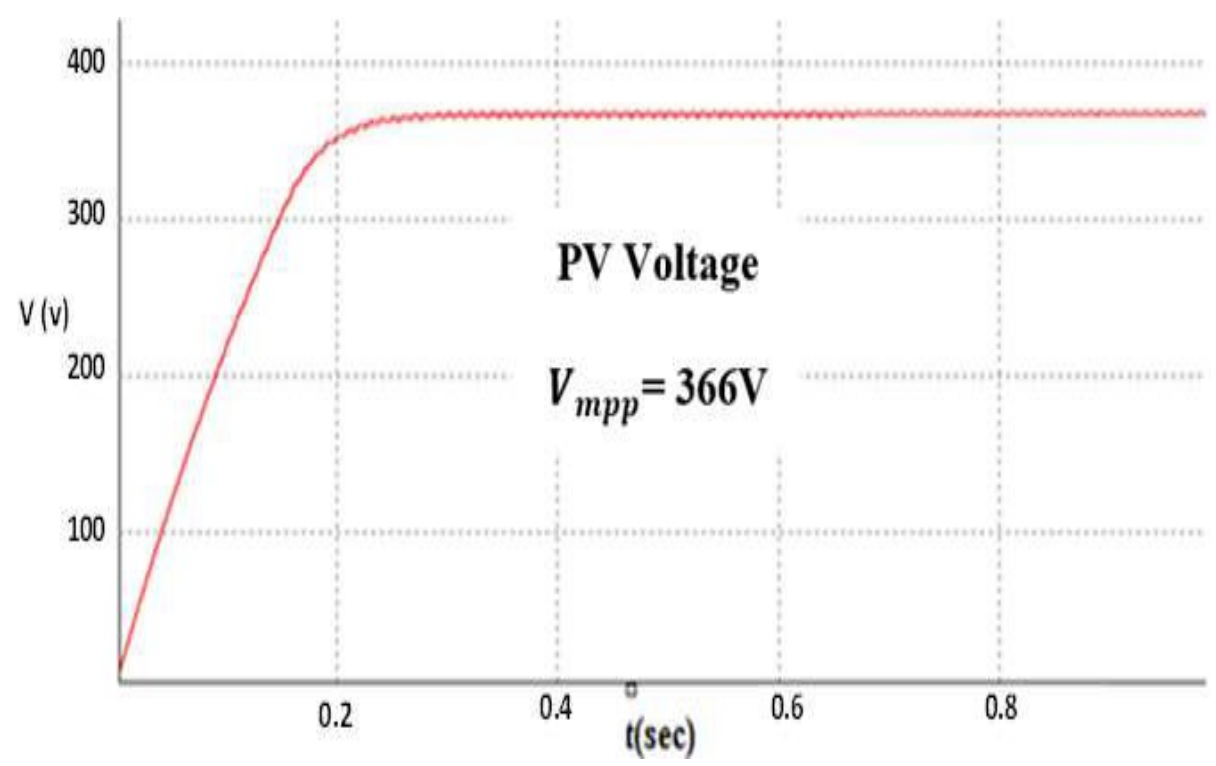

Fig. 13 - PV MPPT voltage

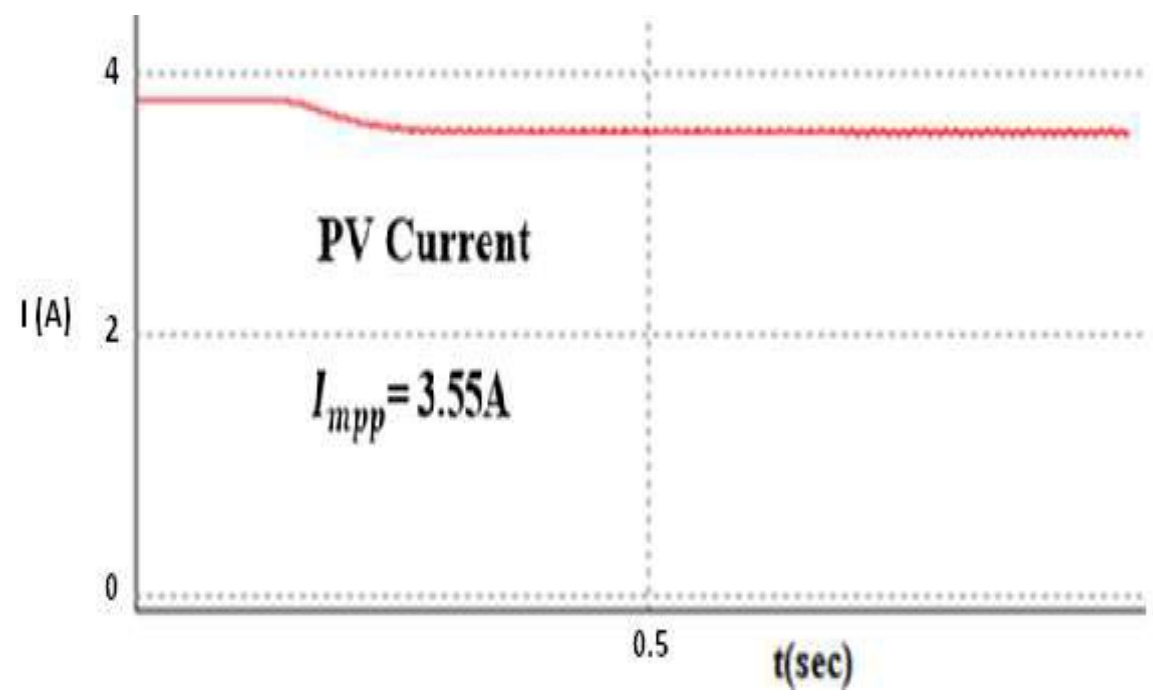

Fig. 14 - PV MPPT current

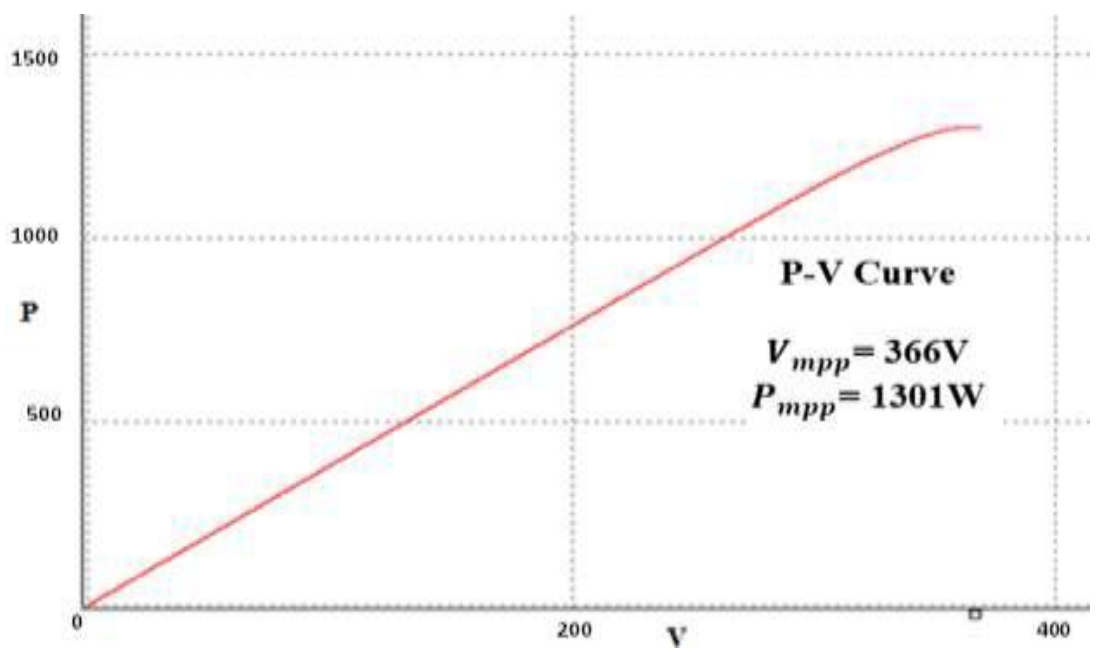

Fig. 15 - PV MPPT power 


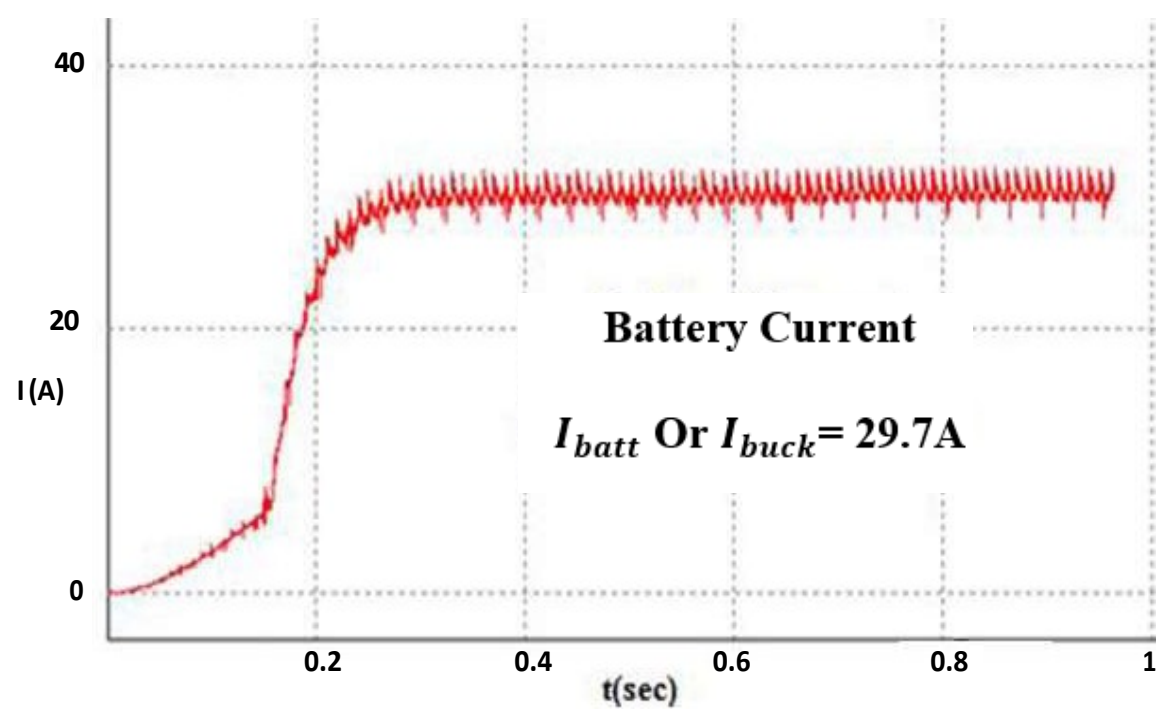

Fig. 16 - Battery charging current

\subsection{Mode 3}

This mode is the same as the previous one but in this case, the battery is assumed to be fully charged, and to save it from overcharging, it is disconnected. So, the duty cycle is not available for controlling. In this case, there is no need to care about MPP, but only the modulation index $(M)$ has to be changed to regulate the output voltage. By formula given below

$$
V_{P}=M V_{P V} \Rightarrow V_{r m s} \sqrt{2}=M V_{P V}
$$

and

$$
\begin{gathered}
P_{L}=V_{L} \times I_{L} \\
\Rightarrow P_{L}=220 \times 4.40=968 \mathrm{~W}
\end{gathered}
$$

Load power is $968 \mathrm{~W}$ and the PV system may generate $1300 \mathrm{~W}$. So, due to the nonlinear nature of the PV curve, PV voltage would become $420 \mathrm{~V}$ as shown in Fig. 17, while it should be about $366 \mathrm{~V}$. This phenomenon is shown from Figs. 17 to 19 .

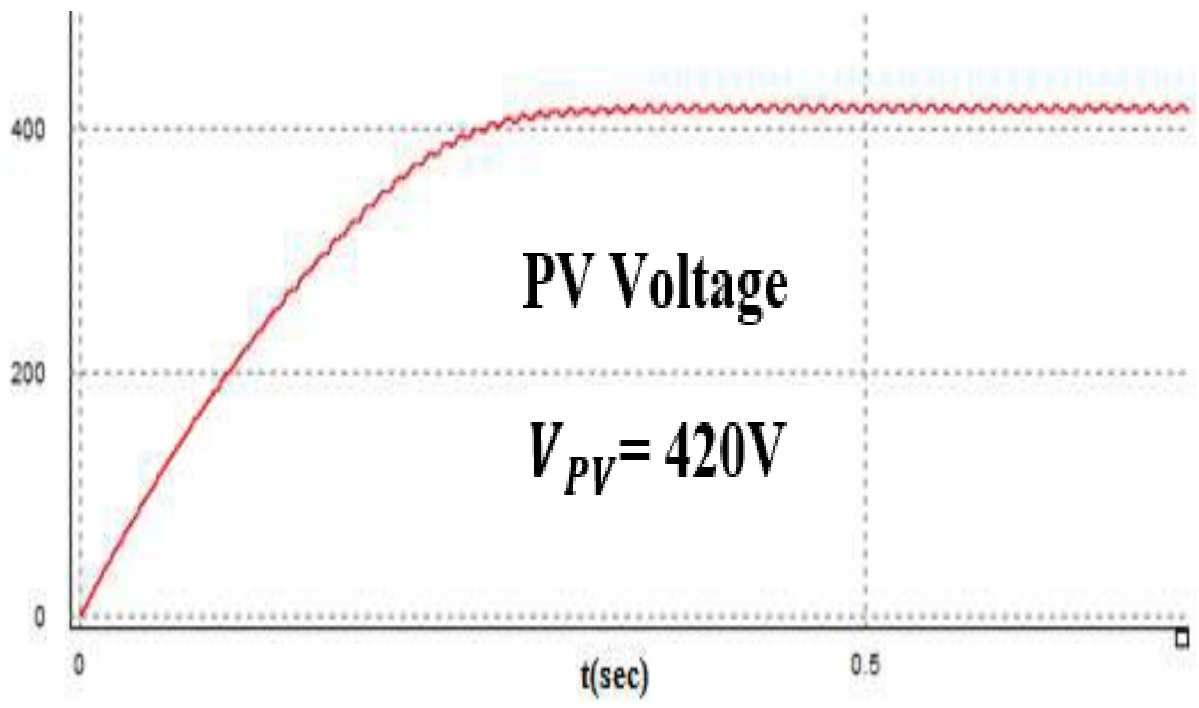

Fig. 17 - PV voltage 


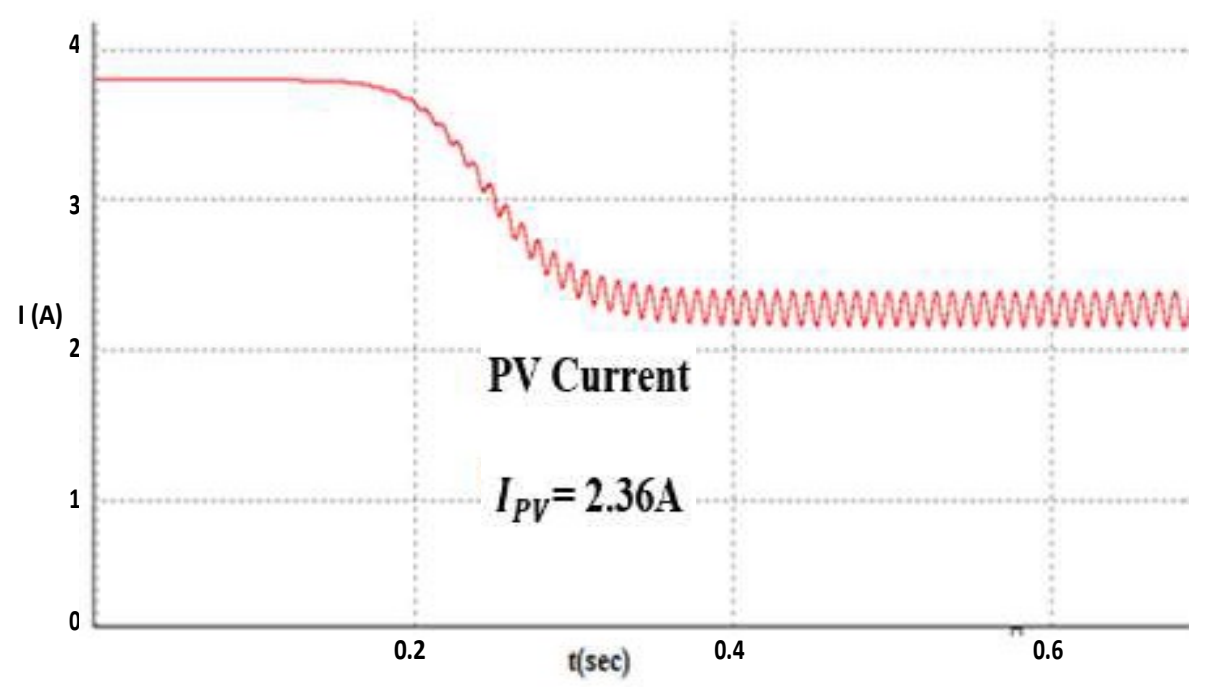

Fig. 18 - PV current

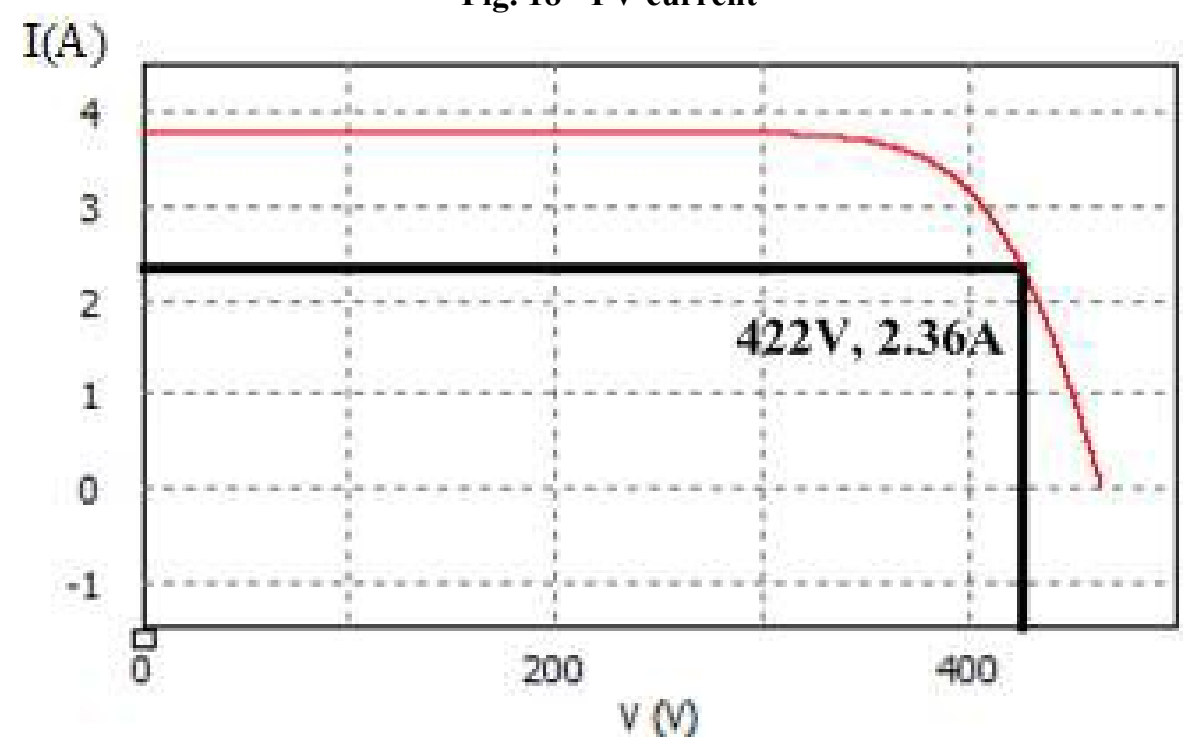

Fig. 19 - I-V curve

Also, in this case, the modulation index is kept at 0.85 and the output voltage at about $250 \mathrm{~V}$. To mitigate the amendments in the voltage to keep it regulated as the load changes, it is essential to keep monitoring PV voltage and varying modulation index. However, in this mentioned case, the modulation index has to be decreased to 0.74 (as calculated from (8)).

\subsection{Mode 4}

In mode 4 , if irradiation level falls, then the system has to share power from the battery which was done in mode 1. So, the results are the same as that of mode 1. In each case mentioned above, the impedance model is verified from the simulation as well as theoretical results, and MPP is achieved.

\subsection{Effect of Varying Modulation Index on $V_{m p p}$}

As already observed, as modulation index is increased, PV voltage may decrease to achieve the same $220 \mathrm{~V}$ load voltages as is evident by the formula given below:

$$
V_{P}=M V_{p v}
$$

A graph (see Fig. 20) is developed to analyze the effect of $M$ on the input voltage to obtain a constant $220 \mathrm{~V}$. 


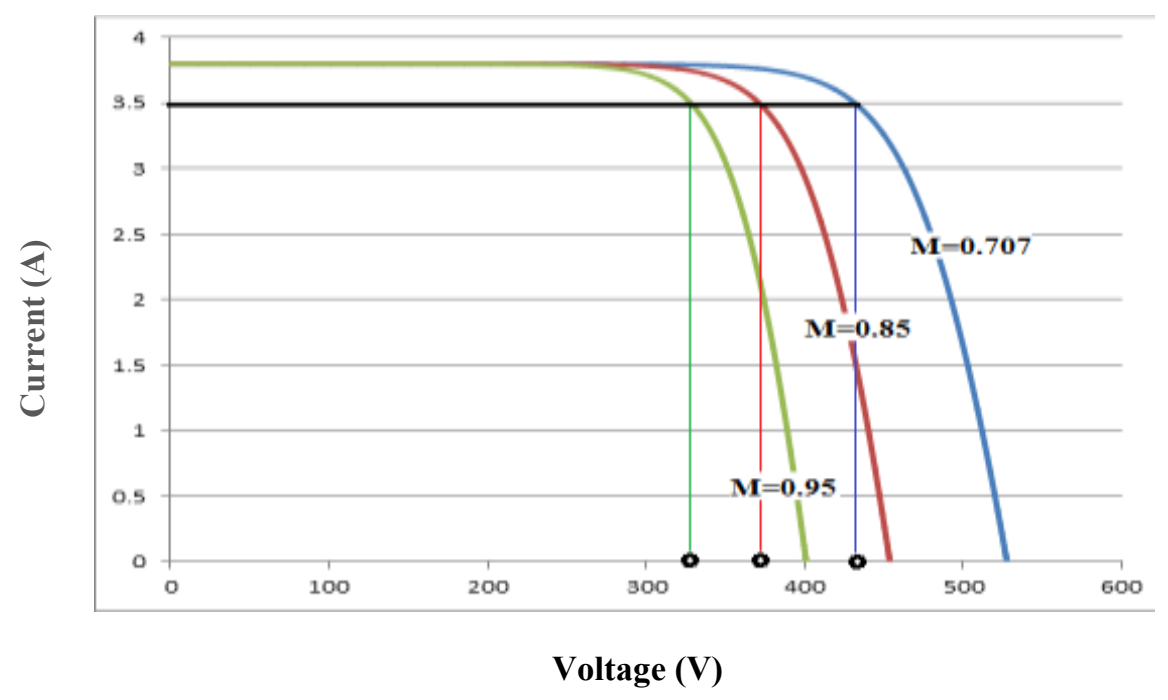

Fig. 20 - Effect of $M$ on MPP voltage

The effect of $M$ on voltage and number of series modules is summarized in Table 1 as well. From Table 1, it is clear that as $M$ increases, $V_{m p p}$ decreases. If the system is operating at a high value of $M$, then the lesser number of series modules has to be connected in series, ensuring the advantage of using high $M$. However, to increase output power, more arrays have to be introduced. Reference [26] suggests that at a high modulation index $M$, THD of output decreases as is evident from Table 2 .

Table 1 - Effect of $M$ on voltage and number of series modules

\begin{tabular}{ccccc}
\hline Load Voltage & No. & $\boldsymbol{M}$ & $V_{m p p}$ & $\begin{array}{c}\mathbf{6 0} \text { W Modules } \\
\text { in Series }\end{array}$ \\
\hline$V_{\text {load }}=311 V_{p-p}$ & 1 & 0.65 & $478 \mathrm{~V}$ & 28 \\
or & 2 & 0.707 & $440 \mathrm{~V}$ & 25 \\
$V_{\text {load }}=311 / 1.4143$ & 3 & 0.85 & $366 \mathrm{~V}$ & 22 \\
$=220 V_{\text {rms }}$ & 4 & 0.95 & $327 \mathrm{~V}$ & 19 \\
\hline
\end{tabular}

Table 2 - Variation of THD by varying $M$

\begin{tabular}{cccc}
\hline $\boldsymbol{M}$ & THD\% & $\boldsymbol{M}$ & THD\% \\
\hline 0.3 & $7.45 \%$ & 0.75 & $3.12 \%$ \\
0.4 & $9.74 \%$ & 0.8 & $3.42 \%$ \\
0.5 & $5.13 \%$ & 0.85 & $2.58 \%$ \\
0.55 & $5.24 \%$ & 0.9 & $2.08 \%$ \\
0.6 & $6.03 \%$ & 0.95 & $2.20 \%$ \\
0.65 & $3.74 \%$ & 1.0 & $2.81 \%$ \\
\hline
\end{tabular}

\section{Conclusion}

This paper describes a novel modeling technique for standalone PV systems. Moreover, the system utilizes a singlestage to overcome the drawbacks of using a two-stage converter topology. Single-stage is achieved by connecting some PV modules in series to get high voltage. Four operating modes are introduced to validate the proposed technique. Bidirectional DC-DC converter acts as a battery charger and discharger. MPPT is achieved by varying the duty cycle of the converter instead of adding a separate DC-DC converter, thus resulting in high gain and efficiency. The proposed modeling technique is validated by the simulation results. This work can be enhanced by using a sophisticated feedback control system, modeling some other types of PV systems such as on-grid and hybrid PV systems, and investigating partial shading effect on model and method to mitigate them. These issues are currently being investigated and will be discussed in the next paper. 


\section{Acknowledgement}

The authors would like to express their gratitude to The University of Lahore, Pakistan for financial, administrative, and technical support.

\section{References}

[1] Shan, R., \& HuiFeng, X. (2010, July). The monetary quantitative methods of environmental and health benefits of renewable energy. In 2010 The 2nd Conference on Environmental Science and Information Application Technology (Vol. 3, pp. 20-23). IEEE.

[2] Masson, G., Latour, M., Rekinger, M., Theologitis, I. T., \& Papoutsi, M. (2013). Global market outlook for photovoltaics 2013-2017. European Photovoltaic Industry Association, 12-32.

[3] de Carvalho Neto, J. T., Salazar, A. O., Lock, A. S., \& Fonseca, D. A. M. (2018). One cycle control for battery connected standalone photovoltaic systems for DC loads. IEEE Latin America Transactions, 16, 1977-1983.

[4] Kumar, N., Saha, T. K., \& Dey, J. (2018). Control, implementation, and analysis of a dual two-level photovoltaic inverter based on modified proportional-resonant controller. IET Renewable Power Generation, 12, 598-604.

[5] De La Fuente, D. V., Rodríguez, C. L. T., Garcerá, G., Figueres, E., \& González, R. O. (2012). Photovoltaic power system with battery backup with grid-connection and islanded operation capabilities. IEEE transactions on industrial electronics, 60, 1571-1581.

[6] Maheswari, L., Rao, P. S., Sivakumaran, N., Ilango, G. S., \& Nagamani, C. (2017). A control strategy to enhance the life time of the battery in a stand-alone PV system with DC loads. IET Power Electronics, 10, 1087-1094.

[7] Moo, C. S., Ng, K. S., \& Hsieh, Y. C. (2008). Parallel operation of battery power modules. IEEE Transactions on Energy Conversion, 23, 701-707.

[8] Lunz, B., Yan, Z., Gerschler, J. B., \& Sauer, D. U. (2012). Influence of plug-in hybrid electric vehicle charging strategies on charging and battery degradation costs. Energy Policy, 46, 511-519.

[9] Duong, M. Q., Nguyen, H. H., Leva, S., Mussetta, M., Sava, G. N., \& Costinas, S. (2016, June). Performance analysis of a $310 \mathrm{Wp}$ photovoltaic module based on single and double diode model. In 2016 International Symposium on Fundamentals of Electrical Engineering (ISFEE) (pp. 1-6). IEEE.

[10] Lee, J. H., Bae, H., \& Cho, B. H. (2006, August). Advanced incremental conductance MPPT algorithm with a variable step size. In 2006 12th International Power Electronics and Motion Control Conference (pp. 603-607). IEEE.

[11] Femia, N., Petrone, G., Spagnuolo, G., \& Vitelli, M. (2005). Optimization of perturb and observe maximum power point tracking method. IEEE transactions on power electronics, 20, 963-973.

[12] Xiao, W., \& Dunford, W. G. (2004, June). A modified adaptive hill climbing MPPT method for photovoltaic power systems. In 2004 IEEE 35th annual power electronics specialists conference (IEEE Cat. No. 04CH37551) (Vol. 3, pp. 1957-1963). IEEE.

[13] Wu, T. F., Chang, C. H., Lin, L. C., \& Kuo, C. L. (2011). Power loss comparison of single-and two-stage gridconnected photovoltaic systems. IEEE Transactions on Energy Conversion, 26, 707-715.

[14] Peter, P. K., \& Agarwal, V. (2016). Photovoltaic module-integrated stand-alone single-stage switched capacitor inverter with maximum power point tracking. IEEE Transactions on Power Electronics, 32, 3571-3584.

[15] Kumar, A., \& Sensarma, P. (2016). A four-switch single-stage single-phase buck-boost inverter. IEEE Transactions on Power Electronics, 32, 5282-5292.

[16] Nehrir, M. H., LaMeres, B. J., Venkataramanan, G., Gerez, V., \& Alvarado, L. A. (2000). An approach to evaluate the general performance of stand-alone wind/photovoltaic generating systems. IEEE Transactions on Energy conversion, 15, 433-439.

[17] Wai, R. J., Wang, W. H., \& Lin, C. Y. (2008). High-performance stand-alone photovoltaic generation system. IEEE Transactions on Industrial Electronics, 55, 240-250.

[18] Ray, O., Mishra, S., Joshi, A., Pradeep, V., \& Tiwari, A. (2012, September). Implementation and control of a bidirectional high-gain transformer-less standalone inverter. In 2012 IEEE Energy Conversion Congress and Exposition (ECCE) (pp. 3233-3240). IEEE.

[19] Caracas, J. V. M., de Carvalho Farias, G., Teixeira, L. F. M., \& de Souza Ribeiro, L. A. (2013). Implementation of a high-efficiency, high-lifetime, and low-cost converter for an autonomous photovoltaic water pumping system. IEEE Transactions on Industry Applications, 50, 631-641.

[20] Kyritsis, A. C., Tatakis, E. C., \& Papanikolaou, N. P. (2008). Optimum design of the current-source flyback inverter for decentralized grid-connected photovoltaic systems. IEEE transactions on energy conversion, 23, 281-293.

[21] Shimizu, T., Wada, K., \& Nakamura, N. (2006). Flyback-type single-phase utility interactive inverter with power pulsation decoupling on the DC input for an AC photovoltaic module system. IEEE transactions on power electronics, 21, 1264-1272. 
[22] Choi, B. Y., Jang, J. W., Kim, Y. H., Ji, Y. H., Jung, Y. C., \& Won, C. Y. (2013, May). Current sensorless MPPT using photovoltaic AC module-type flyback inverter. In 2013 IEEE International Symposium on Industrial Electronics (pp. 1-6). IEEE.

[23] Shimizu, T., Wada, K., \& Nakamura, N. (2002, June). A flyback-type single phase utility interactive inverter with low-frequency ripple current reduction on the DC input for an AC photovoltaic module system. In 2002 IEEE 33rd Annual IEEE Power Electronics Specialists Conference. Proceedings (Cat. No. 02CH37289) (Vol. 3, pp. 14831488). IEEE.

[24] Sher, H. A., Rizvi, A. A., Addoweesh, K. E., \& Al-Haddad, K. (2016). A single-stage stand-alone photovoltaic energy system with high tracking efficiency. IEEE Transactions on Sustainable Energy, 8, 755-762.

[25] Das, M., \& Agarwal, V. (2015). Novel high-performance stand-alone solar PV system with high-gain highefficiency DC-DC converter power stages. IEEE Transactions on Industry Applications, 51, 4718-4728.

[26] Aboadla, E. H. E., Khan, S., Habaebi, M. H., Gunawan, T., Hamidah, B. A., \& Yaacob, M. B. (2016, January). Effect of modulation index of pulse width modulation inverter on Total Harmonic Distortion for Sinusoidal. In 2016 International Conference on Intelligent Systems Engineering (ICISE) (pp. 192-196). IEEE. 